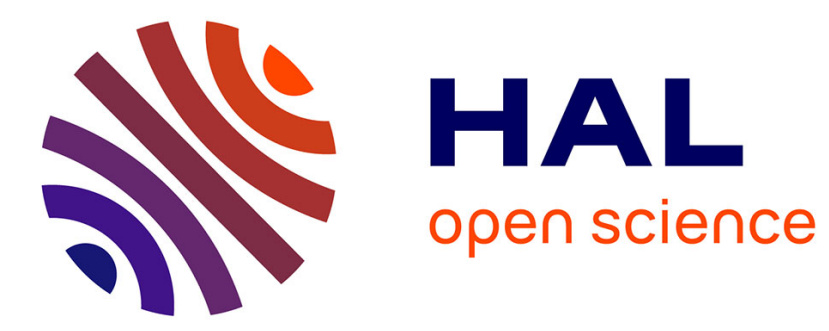

\title{
Environment and sex control lifespan and telomere length in wild-derived African killifish
}

Martin Reichard, Kety Giannetti, Tania Ferreira, Milan Vrtílek, Matej

Polačik, Radim Blažek, Miguel Godinho Ferreira

\section{To cite this version:}

Martin Reichard, Kety Giannetti, Tania Ferreira, Milan Vrtílek, Matej Polačik, et al.. Environment and sex control lifespan and telomere length in wild-derived African killifish. 2020. hal-02988422

\section{HAL Id: hal-02988422 \\ https://hal.science/hal-02988422}

Preprint submitted on 4 Nov 2020

HAL is a multi-disciplinary open access archive for the deposit and dissemination of scientific research documents, whether they are published or not. The documents may come from teaching and research institutions in France or abroad, or from public or private research centers.
L'archive ouverte pluridisciplinaire HAL, est destinée au dépôt et à la diffusion de documents scientifiques de niveau recherche, publiés ou non, émanant des établissements d'enseignement et de recherche français ou étrangers, des laboratoires publics ou privés. 


\section{Environment and sex control lifespan and telomere length}

4 Martin Reichard*1,2, Kety Giannetti*3, Tania Ferreira ${ }^{3}$, Milan Vrtílek ${ }^{1}$, Matej Polačik ${ }^{1}$, Radim

$5 \quad$ Blažek $^{1}$ and Miguel Godinho Ferreira ${ }^{3,4}$

6 1. Czech Academy of Sciences, Institute of Vertebrate Biology, Květná 8, 60365 Brno, Czech

$7 \quad$ Republic.

8 2. Department of Botany and Zoology, Faculty of Science, Masaryk University, Kotlářská 2,

961137 Brno

10 3. Instituto Gulbenkian de Ciência, 2781-901 Oeiras, Portugal

11 4. Institute for Research on Cancer and Aging of Nice (IRCAN), Université Côte d'Azur, UMR7284 U1081 UNS, 06107 Nice, France.

$14 *$ These authors contributed equally in this work

15

For correspondence: Miguel-Godinho.FERREIRA@unice.fr and reichard@ivb.cz

17

18 Keywords: killifish; sex differences; longevity; comparative analysis; telomere 


\section{ABSTRACT}

21 Telomere length is correlated positively with longevity at the individual level, but negatively

22 when compared across species. Here, we tested the association between lifespan and telomere

23 length in African annual killifish. We analyzed telomere length in 18 Nothobranchius strains

24 derived from diverse habitats and measured the laboratory lifespan of 14 strains of $N$. furzeri

25 and $N$. kadleci. We found that males had shorter telomeres than females. The longest telomeres

26 were recorded in strains derived from dry region where male lifespans were shortest. At the

27 individual level, we detected a weak negative association between rapid juvenile growth and

28 shorter telomeres in early adulthood. Overall, average telomere length was a good descriptor of

29 telomere length distribution. However, within-individual telomere length spread was not related

30 to any pattern. This substantial variation in telomere length between strains from different

31 environments provides killifish as powerful tool to understand the evolutionarily adaptive value

32 of telomere length. 


\section{INTRODUCTION}

Telomeres comprise the ends of all eukaryotic chromosomes and are composed of repetitive DNA sequences and specialized proteins (de Lange 2005). Telomeres protect chromosome ends from illegitimate DNA repair and, through the action of telomerase, from DNA replicationrelated chromosome shortening (Olovnikov 1973, Greider and Blackburn 1989, Forsyth, Wright et al. 2002). Telomere attrition results in the loss of its protective function and cell proliferation arrest. Critically short telomeres trigger DNA damage responses and genomic instability, a hallmark of aging (López-Otín, Blasco et al. 2013). Apart from the "endreplication problem", several other factors have been linked to telomere attrition. These include exposure to oxidative damage (Opresko, Fan et al. 2005, Glade and Meguid 2015, Ahmed and Lingner 2018), inflammation (Zhang, Rane et al. 2016), and environmental stressors (Epel, Blackburn et al. 2004, Chatelain, Drobniak et al. 2020). Cells with short telomeres may undergo apoptosis and, if compensatory cell proliferation is no longer available, short telomeres result in cell senescence and inflammation, ultimately disrupting tissue homeostasis (Roos and Kaina 2006, Armanios, Alder et al. 2009, Carneiro, Henriques et al. 2016, El Mai, Marzullo et al. 2020). Impaired tissue homeostasis is at the core of ageing-associated degeneration.

Although not completely understood, telomere shortening in animals, particularly in humans, is a strong promoter of aging-associated degenerative phenotypes (Armanios, Alder et al. 2009, Moskalev, Shaposhnikov et al. 2013). Short telomeres are closely associated with age pathologies such as diabetes mellitus, cardiovascular disease, atherosclerosis, dementia and various cancers (Kota, Bharath et al. 2015, Sethi, Bhat et al. 2016, Aviv, Anderson et al. 2017, Martinez and Blasco 2018). Loss-of-function mutations in genes related to telomere maintenance are responsible for several human syndromes, such as dyskeratosis congenita, aplastic anemia and idiopathic pulmonary fibrosis (Vulliamy, Marrone et al. 2004, Yamaguchi, 
Calado et al. 2005, Tsakiri, Cronkhite et al. 2007). Similarly, studies using animal models have revealed that mutations in telomerase give rise to age-associated deficiencies and reduction of lifespan (Rudolph, Chang et al. 1999, Henriques, Carneiro et al. 2013, Harel and Brunet 2015, Lex, Gil et al. 2020).

Previous studies have highlighted an association between telomere length and lifespan (Fick, Fick et al. 2012, Heidinger, Blount et al. 2012, Barrett, Burke et al. 2013, Ibanez-Alamo, Pineda-Pampliega et al. 2018). Correlative analyses suggest that, within the same species, individuals with shorter telomeres are prone to disease and die earlier (Salomons, Mulder et al. 2009, Fairlie, Holland et al. 2016, Wilbourn, Moatt et al. 2018), but it remains unclear whether telomere length is an indicator of individual condition (Glei, Goldman et al. 2016). While the protective functions of telomeres are conserved across eukaryotes, telomere shortening with age is not observed in all species (Monaghan and Ozanne 2018, Burraco, Comas et al. 2020). Unlike humans, some animals do not repress telomerase in somatic cells and maintain long telomeres throughout their lives (Sherr and DePinho 2000, Forsyth, Wright et al. 2002). Across species, long telomeres do not correlate with longer lifespans. In fact, longer-lived mammals possess shorter telomeres than short-lived mammals, such as mice and rats (Gomes, Ryder et al. 2011). Instead, the rate of telomere attrition, rather than telomere length per se, appears to correlate with species-specific lifespans (Haussmann, Winkler et al. 2003, Epel, Merkin et al. 2008, Boonekamp, Mulder et al. 2014, Dantzer and Fletcher 2015, Whittemore, Vera et al. 2019).

In humans, women typically have longer telomeres, experience lower rates of telomere attrition and live longer (Gardner, Bann et al. 2014, Lapham, Kvale et al. 2015, Aubert, Baerlocher et al. 2012). While not universal across species, sex differences in telomere length have been reported in most vertebrate taxa studied (reviewed in Barret and Richardson 2011). 
However, many of these studies report relatively weak effects that fail to be reproduced. It is also not consistent which sex possesses longer telomeres and it is even less clear whether sexspecific telomere length correlates with lifespan or individual condition (Barrett and Richardson 2011, Wilbourn, Moatt et al. 2018, Bauch, Gatt et al. 2020). Hormonal profiles and reproductive stress have been suggested as the causes of differential telomere shortening, but the mechanisms underlying sex differences in telomere length remain largely unexplored (Hartmann, Reichwald et al. 2009, Barrett and Richardson 2011, Graf, Hartmann et al. 2013, Bauch, Gatt et al. 2020).

We performed a comparative experimental study to examine the association between telomere length and lifespan in African annual killifishes from the genus Nothobranchius. This group of small and short-lived fishes, and the Turquoise killifish (Nothobranchius furzeri) in particular, has recently been established as a model for aging studies. These fish combine the advantages of available resources (reviewed in Cellerino, Valenzano et al., 2016; Hu and Brunet 2018), cheap and convenient husbandry (Polačik, Blažek et al. 2016) and, importantly, links between laboratory studies and natural populations (Reichard and Polačik 2019). We used a set of strains derived from natural populations, which have evolved along a cline of aridity in their natural habitat (Tozzini, Dorn et al. 2013, Blažek, Polačik et al. 2017), to test how variation in lifespan among strains relates to telomere length. As an extension of the association of longer telomeres with shorter-lived species (Gomes, Ryder et al. 2011), we predicted that telomere length would be negatively associated with lifespan across strains.

Within populations, male killifish are shorter lived than females (Reichard, Polačik et al. 2014, Reichard, Blažek et al. 2020), leading to a prediction that females may possess longer telomeres than males. Telomerase expression can be detected in Nothobranchius throughout their lives (Hartmann, Reichwald et al. 2009), but telomeres do shorten with age. Hartmann, 
106 Reichwald et al. (2009) reported that in a longer-lived strain (MZM 0304), old adults (26 weeks

107 old) had $8 \%$ and $27 \%$ shorter telomeres in muscle and skin tissues, respectively, compared to

108 young adults (5 weeks old). In contrast, telomeres do not appear to shorten between the ages of

1095 and 13 weeks in the short-lived GRZ strain (Hartmann, Reichwald et al. 2009).

110 We took advantage of the diversity of killifish strains derived from different wild

111 populations and data on their natural habitats. We measured the lifespan of nine $N$. furzeri

112 strains and five strains of the closely related N. kadleci (Bartáková, Reichard et al. 2015) in

113 laboratory conditions. We estimated telomere length in 12 of these strains at the time of sexual

114 maturity (4 weeks) and linked them to juvenile growth. Using Telomere Restriction Fragment

115 (TRF) by Southern blot analysis, we tested the statistical distribution of telomere length within

116 individual samples to understand how variability in telomere length, rather than its mean, is

117 associated with juvenile growth and lifespan estimates. Finally, we report telomere lengths for

118 another seven strains of five other Nothobranchius species with various lifespans. 


\section{RESULTS}

\section{Lifespan: males from dry-region strains have shorter lifespans}

121 We used strictly standardized conditions to estimate the lifespan of 14 strains from the $N$.

122 furzeri-N. kadleci species complex. Across strains, median lifespan varied almost twofold, from

123151 days (inbred GRZ strain) to 276 days (Table 1). Overall, males were shorter lived than

124 females (Mixed effects Cox model controlling for population identity nested within species

125 identity: $\mathrm{z}=5.39, \mathrm{p}<0.001)$. This pattern was especially consistent in $N$. furzeri. Sex-specific

126 lifespan estimates for each strain are detailed in Table 1.

The $N$. furzeri-kadleci complex is composed of locally constrained populations living in small ephemeral pools which are genetically distinct from adjacent populations (Bartáková, Reichard et al. 2013). All strains used in our analyses were derived from natural populations,

130 for which we knew the exact location of their original pool. We characterized the environmental

131 conditions in which these natural populations lived using long-term data on precipitation

132 (www.worldclim.org). The wild populations are distributed along a clear cline, where increasing altitude and decreasing latitude are associated with lower precipitation (Figure 1).

134 Our comprehensive set of wild-derived strains confirmed previous conclusions using contrasts 135 between pairs of strains (Tozzini, Dorn et al., 2013, Blažek, Polačik et al., 2017) that median 136 lifespan correlates positively with local precipitation $\left(t_{12}=2.64, \mathrm{P}=0.021\right)$ for data on both 137 sexes pooled). Interestingly, for sex-specific lifespan estimates (which were not tested in 138 previous studies), this relationship holds in males (LM: $\left.t_{12}=3.19, \mathrm{p}=0.008\right)$ but not females

$139\left(t_{13}=0.32, \mathrm{p}=0.752\right)($ Figure 2$)$. Our results indicate that males, but not females, from arid 140 regions have shorter median lifespans than those from humid regions, suggesting that perhaps 141 strains from arid regions would exhibit shorter telomeres. 


\section{Average telomere length is a good descriptor of telomere length distribution}

144 Telomere length was estimated using Telomere Restriction Fragment (TRF) by Southern blot

145 analysis on samples from 11 wild derived populations (10 fish per population, with equal sex

146 ratio). The final sample size $(n=92$, Table 1$)$ was slightly reduced due to lower quality of

147 genomic DNA. All fish examined were young adults of the same age (28 days old), except for

148 a single population (p222; 69 days old). All tissue samples comprised small biopsies from the 149 caudal fin.

150 We first explored the relationships between various descriptors of telomere length 151 distributions. Using a biplot based on a Principal Component Analysis (PCA) of the data

152 distribution parameters (Figure 3), we found that disparate measures of telomere length (mean, 153 median, 5-95\% quantiles) were all highly positively correlated (Supplementary Table 1). The 154 measures of telomere length variability within individual fish (inter-quartile range and coefficient of variation) were not strongly related to the estimates of telomere length (Figure 3,

156 Supplementary Table 1). Based on this information, we used the mean as the measure of 157 telomere length and the coefficient of variation $(\mathrm{CV})$ as a measure of intra-individual telomere 158 length variability in further analyses. These two measures were not correlated (Pearson, $r=$ $1590.01, \mathrm{n}=92, \mathrm{p}=0.940)$.

Telomere length is shorter in males and in faster growing individuals

162 The exploratory analysis revealed a difference in mean telomere length, from 5.29 (s.e. 0.42 ) to 9.92 (s.e. 0.42) kbp across various strains (Figure 4, Supplementary Figure 1, Supplementary

164 Table 2). When comparing telomere length between males and females, we accounted for inter165 strain variation using strain ID as a random effect. 
We first tested how parameters of telomere length vary in relation to sex and juvenile growth (measured as individual body size at age of 28 days). Our set of candidate models contained the two explanatory variables and their interaction, along with a null model (Table 2). Candidate models were fitted to the data and compared using the Akaike Information Criterion corrected for small sample size (AICc). The best model contained only sex (Table 2a) and demonstrated that males had shorter telomeres than females (Linear Mixed Model with strain ID modelled as a random factor: $\left.F_{1,80.4}=23.13, \mathrm{P}<0.001\right)$. Across strains, mean telomere length was $7.37 \mathrm{kbp}$ (s.e. 0.45) in females and 6.18 (s.e. 0.24) in males. Strain identity explained a large part of variation in all models; the values of $\mathrm{R}^{2} \mathrm{GLMM}$ conditional were approximately 6 times larger than $\mathrm{R}^{2}$ GLMM marginal (Table 2). rapid juvenile growth (i.e. large size at the age of 28 days) was associated with relatively shorter

178 telomere length $\left(F_{1,88.9}=4.47, \mathrm{P}=0.037\right)$ but the trend became weaker and statistically nonfish) $\left(F_{1,75.7}=3.52, \mathrm{P}=0.064\right.$; Supplementary Table 3$)$. their interaction (Table 2b).

\section{Telomere length tends to be shorter in strains from more humid environments}

We then tested whether total annual precipitation in the original habitat, which is associated included sex differences in telomere length $\left(F_{1,80.5}=23.08, \mathrm{P}<0.001\right)$ and a trend towards negative association with precipitation totals (Figure $5 ; F_{1,9.0}=4.11, \mathrm{P}=0.072$ ), suggesting that 

3b), although it varied considerably across strains (Figure $4 b$ ).

\section{Telomere length is not associated with median lifespan}

194 Given that the sexes differed in their lifespans, we used sex-specific lifespan estimates to test 195 the association between telomere length and population-level longevity (Figure 6). The best 196 model (Table 4a) confirmed sex differences in telomere length $\left(F_{1,8071}=18.57, \mathrm{P}<0.001\right)$, but

197 did not demonstrate a link between mean telomere length and median lifespan estimate $\left(F_{1,88.7}\right.$ $198=2.39, \mathrm{P}=0.126)$. Therefore, consistent with previous studies at the inter-specific level, telomere length does not appear to predict longevity among different killifish strains.

For telomere length variability (CV), none of the candidate models was better than a null model (Table 4b).

\section{Telomere length in other Nothobranchius species}

204 Finally, we expanded telomere length analysis to three other Nothobranchius species from

205 Mozambique (N. orthonotus, $N$. pienaari, $N$. rachovii) that widely coexist with $N$. furzerikadleci species complex (Reichard, Janáč et al. 2017). We also included two species from Tanzania (N. rubripinnis, N. eggersi), where a more humid climate is linked to a longer duration of wet habitat phase (Reichard 2015).

Telomere length among these species was comparable (range 3.6-7.3 kbp, Supplementary

211 was generally longer for the relatively shorter-lived N. orthonotus (strain MZCS 002 Limpopo:

212 mean (s.e.) $=5.63(0.29), \mathrm{n}=4$; MZCS 528 Beira: $6.03(0.35), \mathrm{n}=2)$ compared to $N$. pienaari 
213 (MZCS 505 Limpopo: 4.29 (0.25), n=4; MZCS 514 Beira: 5.86 (0.29), n=3) and N. rachovii

214 (MZCS 096 Beira: 3.65, n=1). Tanzanian Nothobranchius species had telomere lengths

215 comparable to Mozambican species (N. rubripinnis T33: $5.60(0.25), \mathrm{n}=4$; N. eggersi T52: 5.45

216 (0.35), n=2). Finally, we also tested telomere length in a highly inbred GRZ strain of $N$. furzeri

217 that was bred under different laboratory conditions from the other fish and, therefore, was not

218 included in the overall analysis. Mean telomere length in the GRZ fish $(7.33(0.29), \mathrm{n}=3)$

219 corresponded to the predicted values based on their origin in a relatively dry region.

\section{DISCUSSION}

Telomeres and telomerase prevent the continuous erosion of chromosome-ends caused by

lifelong cell division. In several species, including humans, telomeres shorten with age and their and function is conserved across eukaryotes and their exhaustion leads to multiple effects both at the cellular and systemic level, causing disruption of organ homeostasis and disease (Armanios, Alder et al. 2009, Carneiro, Henriques et al. 2016). Traditionally, telomere length has been considered indicative of "biological age" and a useful proxy to predict individual health status and longevity. However, evidence from several non-human vertebrates now contradicts this assumption as simplistic.

In our large sample of wild-derived annual killifish strains obtained from a gradient of environmental conditions and natural lifespans, we found that telomere length varied across 233 strains and tended to be shorter in populations that came from more humid regions where 234 populations naturally live longer. The natural habitats of annual killifish are seasonal pools in 235 the African savannah. They are inundated during the rainy season, fish hatch, grow rapidly and 
the dry season and killifish populations persist as dormant eggs in the pool sediment. The wet

238 phase may vary from a few weeks to several months (Vrtílek, Žák et al. 2018b) depending on

239 the amount of precipitation in the area (Blažek, Polačik et al. 2017). Habitat duration, which

240 varies considerably across the precipitation gradient of killifish distribution, determines

241 maximum lifespans. Male lifespans in our laboratory assays were strongly associated with

242 annual precipitation levels in their area of their origin, though female lifespans were not.

243 Consistent with previous observations across species (Gomes, Ryder et al. 2011), killifish from

244 more humid regions (and hence with longer lifespans, both predicted and observed) had shorter

245 telomeres than those from arid regions. This complements an analogous trend found across

246 mammalian species (Gomes, Ryder et al. 2011) and demonstrates that telomere length

247 differences among populations reflect patterns found among species.

Alternatively, telomere length differences across strains may simply have been fixed 249 through genetic drift. Natural Nothobranchius populations are genetically distinct units 250 (Bartáková, Reichard et al. 2015) but are more fragmented and have smaller effective population sizes in the dry part of their range (Willemsen, Cui et al. 2020). Killifish populations

252 from dry regions experience increased mutation load, leading to a reduction in their lifespans 253 (Cui, Medeiros et al. 2019, Willemsen, Cui et al. 2020). However, our data demonstrate that 254 dry-region populations tend to have longer telomeres, including the highly inbred GRZ 255 population with apparently the strongest mutation load. This trend is further strengthened by 256 the telomere length of other three Nothobranchius species from Mozambique (N. orthonotus, $257 N$. pienaari, $N$. rachovii), widely coexisting with the $N$. furzeri-kadleci species complex and 258 two species from a more humid region in coastal Tanzania (N. eggersi, N. rubripinnis). 259 Telomere length was comparable in all these longer-lived species (Blažek, Polačik et al. 2017, 260 Wildekamp 2004) but generally shorter than in the $N$. furzeri-N. kadleci complex, suggesting 
that genetic drift is unlikely a driver of such consistent population-specific differences in telomere length.

Sex differences in telomere length were consistent across strains (Supplementary Table 2 ), with male telomeres $22 \%$ shorter on average. Remarkably, males also had consistently shorter lifespans than females in all nine $N$. furzeri (but only in 2 of $5 \mathrm{~N}$. kadleci) populations. All our experimental fish were housed in social tanks. This pattern of sex differences in lifespan corroborates conclusions from a separate study (Reichard, Blažek et al. 2020) where N. furzeri (but not $N$. kadleci) males in social tanks suffered higher baseline mortality than females. Higher male mortality was not reflected in sex differences in any measure of functional aging (oxidative stress, kidney and liver histopathology, accumulation of lipofuscin) (Reichard, Blažek et al. 2020). Individual variation in telomere length distribution did not differ between the sexes, discounting the possibility that females possess mechanisms for countering cells with short telomeres. However, it is plausible that males are more susceptible to telomere erosion due to higher hormonal and environmental stress. Nothobranchius fish display remarkable sexual dimorphism and dichromatism. Males are larger and more brightly colored than females and continuously compete for mating opportunities (Cellerino, Valenzano et al., 2016, Reichard and Polačik 2019). Male reproductive strategy (higher growth, investment in bright coloration 278 and aggressive interactions) therefore implicates a higher metabolic cost and more rapid growth 279 than the female reproductive strategy (Bonduriansky, Maklakov et al. 2008). This may underlie 280 the faster decline in telomere length in males, which we recorded as a shorter telomere length 281 in young adult males.

Even within the sexes, rapid juvenile growth tended to be associated with relatively shorter telomere length. Our sampling at the age of 28 days encompassed the period of most rapid growth rate in Nothobranchius lifespan, with fish growing from an initial body length of 
hypothesis that growth rate, primarily in early life, at least partly affects the kinetics of telomere erosion and overall telomere length. We now plan a follow-up study with repeated longitudinal sampling of the same individuals to test this hypothesis.

Studies on telomere length in the field of ecology and evolution typically use real-time PCR assays to determine Telomere-to-Single Copy Gene (T/S) ratio which provides an indirect estimate of mean telomere length (Lai, Wright et al. 2018). However, the detrimental effects of telomere shortening are expected to arise from a frequently dividing subpopulation of cells within a particular tissue, which may not be well represented in the T/S ratio. We estimated telomere length using the robust TRF method that yields a direct distribution of telomere fragments in the sample. Importantly, we confirmed that estimates of mean values are a useful proxy for telomere length distribution as they closely correlated with other parameters of telomere length distribution, including a set of 5-95\% quantiles. Thus, mean telomere length represents a suitable estimate of telomere kinetics in adult Nothobranchius killifishes.

299 Additionally, the measure of telomere length variability within an individual, the coefficient of variation, was not associated with any pattern in our data (between sexes, among strains, or in juvenile growth). This suggests that the dispersion in telomere length distribution is a strainspecific character controlled by regulatory pathways other than those used in determining 303 telomere length. As telomeres shorten, wider telomere distributions will give rise to more 304 critically short telomeres than narrow ones, thus providing an independent parameter to control telomere decline with age.

Overall, our results demonstrate a clear variation in telomere length between sexes and 307 environments among wild-derived strains of Nothobranchius fishes and highlight their suitability for understanding the adaptive value of telomere length across individuals, populations, and species. 


\section{MATERIALS AND METHODS}

\section{Fish origin and environmental data}

312 Study strains were descendants of wild populations imported from Mozambique and the

313 adjacent area of Zimbabwe. In this region, a clear gradient of aridity is generated by a decrease

314 in total precipitation with increasing distance from the coast, increasing altitude and decreasing

315 latitude associated with lower precipitation (Figure 1; Blažek, Polačik et al. 2017). Fish from

316 wild populations were imported between 2009 and 2012 during dedicated expeditions and wild-

317 derived strains were maintained in the Institute of Vertebrate Biology (IVB) in Brno, Czech

318 Republic according to published protocol (Polačik, Blažek et al. 2016). One strain (GRZ) was

319 imported in 1969 from Zimbabwe and another strain (MZM-0410, coded as pMZM in our 320 dataset) was imported in 2004. The origin of each study strain is illustrated in Figure 1 and GPS

321 coordinates are provided in Table 1. Other strains of Mozambican (N. orthonotus, N. pienaari,

$322 N$. rachovii) and Tanzanian species (N. eggersi and N. rubripinnis) originate from our own

323 imports between 2008 and 2017 (Supplementary Table 4). Housing conditions were the same

324 for all species.

Data on precipitation (represented by annual rainfall totals) and aridity were downloaded

326 from www.worldclim.org. Aridity was measured as aridity index (total precipitation/model-

327 estimated evapotranspiration). Given that precipitation and aridity were highly collinear

328 (Pearson $\mathrm{r}=0.989, \mathrm{n}=12, \mathrm{P}<0.001$ ), we only present analyses using total precipitation. 
331 Fish were kept at the IVB facility under standard conditions and care was taken to minimize 332 inbreeding (i.e. a large number of fish were sources of offspring for the next generation, though 333 no specific breeding design was followed).

For the estimates of lifespan, eggs of 14 strains were hatched simultaneously. The eggs were kept in diapause at $19^{\circ} \mathrm{C}$. Two weeks prior to hatching, the eggs were placed in $28^{\circ} \mathrm{C}$ to initiate release from Diapause II and development to prehatching stage. In August 2016, the incubation substrate (peat) was watered with dechlorinated tap water (conductivity $338600 \mathrm{microS} / \mathrm{cm}$, temperature $16^{\circ} \mathrm{C}$ ) in a $2 \mathrm{~L}$ tank. Fish hatched within 1 day and were

339 immediately fed on freshly hatched Artemia nauplii. After 5 days, fish were moved to larger 340 tanks (40 L) and their density was standardized across strains. At 3 weeks, fish were weaned 341 from Artemia nauplii to frozen chironomid larvae, a standard diet of captive Nothobranchius 342 (Polačik, Blažek et al. 2016). survfit function in the survival package. 95\% confidence intervals for median lifespan estimates were calculated using a log-log function.

\section{Telomere length estimates}

351 Telomere length was estimated through Telomere Restriction Fragment (TRF) analysis

352 followed by Southern blotting. Fish from 12 strains (all strains used in lifespan estimate except 353 for GRZ, p108, and p109) were hatched on 6 May 2019, following the same protocol as for 
354 lifespan estimates. When all fish were sexually mature, at the age of 28 days, a biopsy from the caudal fin was taken from 5 male and 5 female fish from each population and flash frozen in liquid nitrogen. Samples of other species were handled in the same way, except they were stored in $100 \%$ ethanol instead of being flash frozen. Due to logistic reasons, one population $(N$. furzeri, MZCS 222) was hatched earlier (26 March 2019) and was older (69 days) at the time of sampling, although it was raised following identical methods and kept in the same room. To account for the potential effect of age on telomere length, we re-ran statistical analyses with this population excluded from the dataset. This population had no effect on the qualitative interpretation and, in the main text, we present the final analysis with this population included. The exception is the test of relationship between body length at sexual maturity (28 days) and telomere length, where we present both the full and truncated datasets as this is where the removal of MZCS 222 strain affected the strength of statistical association.

Genomic DNA was extracted using a lysis buffer (Thermo Scientific \#K0512) supplemented with $1 \mathrm{mg} / \mathrm{ml}$ Proteinase K $(0.5 \mathrm{mg} / \mathrm{ml}$ final concentration, Sigma, MO, USA) and RNase A (1:100 dilution, Sigma, MO, USA). Samples were incubated at $50^{\circ} \mathrm{C}$ for $18 \mathrm{~h}$ in chloroform (Sigma, MO, USA) and chloroform-isoamyl alcohol extraction (Sigma, MO, USA).

371 Following quantification and normalization, genomic DNA was digested with RsaI and HinfI 372 enzymes (NEB, MA, USA) for $12 \mathrm{~h}$ at $37^{\circ} \mathrm{C}$. Digested samples were electrophoresed on a 20 cm $0.6 \%$ agarose gel, in $0.5 \%$ TBE buffer, at $4^{\circ} \mathrm{C}$ for $17 \mathrm{~h}$ at 110 constant voltage. Southern 374 blotting was performed as previously described (Kimura, Stone et al. 2010) with minor changes; 375 a telomere probe, $(\mathrm{CCCTAA})_{4}$, labelled with $[\alpha-32 \mathrm{P}]$-dCTP through the Prime-it II random 376 primer labelling kit (Stratagene) was used. Raw data from Southern Blots are presented as 377 Supplementary Figure 1. 


\section{Statistical analysis}

380 We first extracted pre-selected parameters of the telomere distribution and analyzed them using

381 Principal Component Analysis (PCA) to test their covariance. We then selected two parameters

382 (mean telomere length and coefficient of variation) representing two uncorrelated descriptors

383 of individual-fish telomere populations for further analyses.

To test the effects of predictors on telomere length and intra-individual variability, we used an information theoretic approach (Burnham and Anderson 2002). A set of biologically plausible models was constructed, with various level of complexity, and including a null

387 (intercept-only) model. All models included strain identity as a random effect to control for non-independence of telomere length across individuals from the same population. We then

389 compared the fit of the models using the Akaike Information Criterion corrected for small

390 sample size (AICc). The best model minimizes AICc value. Model within $\triangle \mathrm{AICc}$ between 2

391 and 5 are considered to have a comparable power.

Analyses were performed in lmer and MuMIn packages in the R 3.5.2 environment.

393 Before applying statistical models, data exploration was undertaken as recommended by Zuur 394 and Ieno et al. (2016). 


\section{Acknowledgement}

396 Funding came from Czech Science Foundation (19-01781S) (to MR), Portuguese Fundação 397 para a Ciência e Tecnologia (POCI-01-0145-FEDER-016390) (to MGF) and French Université 398 Côte d'Azur Academie 4 Installation Grant (to MGF). All work was carried out in accordance 399 with relevant guidelines and regulations. Collection of wild strains complied with legal 400 regulations of Mozambique (collection licenses: DPPM/053/7.10/08, 175/154/ 401 IIP/2009/DARPE, DPPM/083/7.10/10， DPPM/330/7.10/10， DPPM/069/7.10/11， 402 DPPM/088/7.10/12). Experimental work was approved by the Ethical Committee of the 403 Institute of Vertebrate Biology (No. 163-12) and by Ministry of Agriculture (CZ 62760203) in 404 accordance with legal regulations of the Czech Republic. We thank R. Spence for valuable 405 comments and English corrections. All primary data are available at Figshare repository (doi: 406 10.6084/m9.figshare.12888566).

\section{Author contributions}

409 MR and MGF conceived and designed the study. RB and MP collected data on lifespan. MV 410 and MR raised fish for telomere length estimates. KG, TF performed genomic DNA extractions, 411 TRF and Southern hybridizations. KG, TF and MGF analyzed and interpreted telomere length. 412 MR and MV conducted statistical analyses. MR, KG and MGF drafted the manuscript. All 413 authors significantly contributed to the final text. 


\section{References}

Ahmed, W. and J. Lingner (2018). "PRDX1 and MTH1 cooperate to prevent ROS-mediated inhibition of telomerase." Genes Dev 32(9-10): 658-669.

Armanios, M., J. K. Alder, E. M. Parry, B. Karim, M. A. Strong and C. W. Greider (2009). "Short telomeres are sufficient to cause the degenerative defects associated with aging." Am J Hum Genet 85(6): 823-832.

Aubert, G., Baerlocher, G. M., Vulto, I., Poon, S. S. and P. M. Lansdorp (2012). "Collapse of telomere homeostasis in hematopoietic cells caused by heterozygous mutations in telomerase genes." PLoS Genet 8(5): e1002696.

Aviv, A., J. J. Anderson and J. W. Shay (2017). "Mutations, Cancer and the Telomere Length Paradox." Trends Cancer 3(4): 253-258.

Barrett, E. L., T. A. Burke, M. Hammers, J. Komdeur and D. S. Richardson (2013). "Telomere length and dynamics predict mortality in a wild longitudinal study." $\underline{\text { Mol Ecol }}$ 22(1): 249-259.

Barrett, E. L. and D. S. Richardson (2011). "Sex differences in telomeres and lifespan." Aging Cell 10(6): 913-921.

Bartáková, V., Reichard, M., Janko, K., Polačik, M., Blažek, R., Reichwald, K., Cellerino, A. and J. Bryja (2013). "Strong population genetic structuring in an annual fish, Nothobranchius furzeri, suggests multiple savannah refugia in southern Mozambique." BMC Evol Biol 13(1): 196.

Bartáková, V., Reichard, M., Blažek, R., Polačik, M. and J. Bryja (2015). "Terrestrial fishes: rivers are barriers to gene flow in annual fishes from the African savanna." J Biogeogr 42(10): 1832-1844.

Bauch, C., M. C. Gatt, J. P. Granadeiro, S. Verhulst and P. Catry (2020). "Sex-specific telomere length and dynamics in relation to age and reproductive success in Cory's shearwaters." Mol Ecol 29(7): 1344-1357.

Blazek, R., M. Polacik, P. Kacer, A. Cellerino, R. Rezucha, C. Methling, O. Tomasek, K. Syslova, E. Terzibasi Tozzini, T. Albrecht, M. Vrtilek and M. Reichard (2017). "Repeated intraspecific divergence in life span and aging of African annual fishes along an aridity gradient." Evolution 71(2): 386-402.

Blazek, R., M. Polacik and M. Reichard (2013). "Rapid growth, early maturation and short generation time in African annual fishes." Evodevo 4(1): 24.

Bonduriansky R., M. A., Zajitschek F. and Brooks R. (2008). "Sexual selection, sexual conflict and the evolution of ageing and life span." Funct Ecol 22: 443-453. 

predicts survival in wild birds." Proc Biol Sci 281(1785): 20133287.

Burraco, P., M. Comas, S. Reguera, F. J. Zamora-Camacho and G. Moreno-Rueda (2020). lizard." Comp Biochem Physiol A Mol Integr Physiol 247: 110741.

454 Carneiro, M. C., C. M. Henriques, J. Nabais, T. Ferreira, T. Carvalho and M. G. Ferreira 455 (2016). "Short telomeres in key tissues initiate local and systemic aging in zebrafish." $\underline{\text { PLoS }}$ 456 Genet 12(1): e1005798.

457 Cellerino, A., D. R. Valenzano and M. Reichard (2016). "From the bush to the bench: the 458 annual Nothobranchius fishes as a new model system in biology." Biol Rev Camb Philos Soc 459 91(2): 511-533.

460 Chatelain, M., S. M. Drobniak and M. Szulkin (2020). "The association between stressors and telomeres in non-human vertebrates: a meta-analysis." Ecol Lett 23(2): 381-398.

462 Christensen, L. L., C. Selman, J. D. Blount, J. G. Pilkington, K. A. Watt, J. M. Pemberton, J. 463 M. Reid and D. H. Nussey (2016). "Marker-dependent associations among oxidative stress, 464 growth and survival during early life in a wild mammal." Proc Biol Sci 283(1840).

465 Cui, R., T. Medeiros, D. Willemsen, L. N. M. Iasi, G. E. Collier, M. Graef, M. Reichard and 466 D. R. Valenzano (2019). "Relaxed Selection Limits Lifespan by Increasing Mutation Load." 467 Cell 178(2): 385-399.

468 Dantzer, B. and Q. E. Fletcher (2015). "Telomeres shorten more slowly in slow-aging wild 469 animals than in fast-aging ones." Exp Gerontol 71: 38-47.

470 de Lange, T. (2005). "Shelterin: the protein complex that shapes and safeguards human 471 telomeres." Genes Dev 19(18): 2100-2110.

472 Dorn, A., Ng'oma, E., Janko, K., Reichwald, K., Polačik, M., Platzer, M., Cellerino, A. and 473 M. Reichard (2011). "Phylogeny, genetic variability and colour polymorphism of an emerging 474 animal model: the short-lived annual Nothobranchius fishes from southern 475 Mozambique." Mol Phyl Evol 61(3): 739-749.

476 El Mai, M., M. Marzullo, I. P. de Castro and M. G. Ferreira (2020). "Opposing p53 and $477 \mathrm{mTOR} / \mathrm{AKT}$ promote an in vivo switch from apoptosis to senescence upon telomere 478 shortening in zebrafish." eLife 9: e54935.

479 Epel, E. S., E. H. Blackburn, J. Lin, F. S. Dhabhar, N. E. Adler, J. D. Morrow and R. M. 480 Cawthon (2004). "Accelerated telomere shortening in response to life stress." Proc Natl Acad 481 Sci U S A 101(49): 17312-17315. 

Seeman (2008). "The rate of leukocyte telomere shortening predicts mortality from cardiovascular disease in elderly men." Aging (Albany NY) 1(1): 81-88.

485

486

487

488

489

490

491

492

493

494

495

496

497

498

499

500

501

502

503

504

505

506

507

508

509

510

511

512

513

514

515

Fairlie, J., R. Holland, J. G. Pilkington, J. M. Pemberton, L. Harrington and D. H. Nussey (2016). "Lifelong leukocyte telomere dynamics and survival in a free-living mammal." Aging Cell 15(1): 140-148.

Fick, L. J., G. H. Fick, Z. Li, E. Cao, B. Bao, D. Heffelfinger, H. G. Parker, E. A. Ostrander and K. Riabowol (2012). "Telomere length correlates with life span of dog breeds." Cell Rep 2(6): 1530-1536.

Forsyth, N. R., W. E. Wright and J. W. Shay (2002). "Telomerase and differentiation in multicellular organisms: turn it off, turn it on, and turn it off again." Differentiation 69(4-5): 188-197.

Gardner, M., D. Bann, L. Wiley, R. Cooper, R. Hardy, D. Nitsch, C. Martin-Ruiz, P. Shiels, A. A. Sayer, M. Barbieri, S. Bekaert, C. Bischoff, A. Brooks-Wilson, W. Chen, C. Cooper, K. Christensen, T. De Meyer, I. Deary, G. Der, A. Diez Roux, A. Fitzpatrick, A. Hajat, J. Halaschek-Wiener, S. Harris, S. C. Hunt, C. Jagger, H. S. Jeon, R. Kaplan, M. Kimura, P. Lansdorp, C. Li, T. Maeda, M. Mangino, T. S. Nawrot, P. Nilsson, K. Nordfjall, G. Paolisso, F. Ren, K. Riabowol, T. Robertson, G. Roos, J. A. Staessen, T. Spector, N. Tang, B. Unryn, P. van der Harst, J. Woo, C. Xing, M. E. Yadegarfar, J. Y. Park, N. Young, D. Kuh, T. von Zglinicki, Y. Ben-Shlomo and t. Halcyon study (2014). "Gender and telomere length: systematic review and meta-analysis." Exp Gerontol 51: 15-27.

Glade, M. J. and M. M. Meguid (2015). "A glance at ... telomeres, oxidative stress, antioxidants, and biological aging." Nutrition 31(11-12): 1447-1451.

Glei, D. A., N. Goldman, R. A. Risques, D. H. Rehkopf, W. H. Dow, L. Rosero-Bixby and M. Weinstein (2016). "Predicting Survival from Telomere Length versus Conventional Predictors: A Multinational Population-Based Cohort Study." PLoS One 11(4): e0152486.

Gomes, N. M., O. A. Ryder, M. L. Houck, S. J. Charter, W. Walker, N. R. Forsyth, S. N. Austad, C. Venditti, M. Pagel, J. W. Shay and W. E. Wright (2011). "Comparative biology of mammalian telomeres: hypotheses on ancestral states and the roles of telomeres in longevity determination." Aging Cell 10(5): 761-768.

Graf, M., A. Cellerino and C. Englert (2010). "Gender separation increases somatic growth in females but does not affect lifespan in Nothobranchius furzeri." PLoS One 5(8): e1 1958.

Greider, C. W. and E. H. Blackburn (1989). "A telomeric sequence in the RNA of Tetrahymena telomerase required for telomere repeat synthesis." Nature 337(6205): 331-337. 
516 Harel, I. and A. Brunet (2015). "The African Turquoise Killifish: A Model for Exploring

517 Vertebrate Aging and Diseases in the Fast Lane." Cold Spring Harb Symp Quant Biol 80:

$518 \quad 275-279$.

519 Hartmann, N., K. Reichwald, A. Lechel, M. Graf, J. Kirschner, A. Dorn, E. Terzibasi, J.

520 Wellner, M. Platzer, K. L. Rudolph, A. Cellerino and C. Englert (2009). "Telomeres shorten

521 while Tert expression increases during ageing of the short-lived fish Nothobranchius furzeri."

522 Mech Ageing Dev 130(5): 290-296.

523 Haussmann, M. F., D. W. Winkler, K. M. O'Reilly, C. E. Huntington, I. C. Nisbet and C. M.

524 Vleck (2003). "Telomeres shorten more slowly in long-lived birds and mammals than in

525 short-lived ones." Proc Biol Sci 270(1522): 1387-1392.

526 Heidinger, B. J., J. D. Blount, W. Boner, K. Griffiths, N. B. Metcalfe and P. Monaghan

527 (2012). "Telomere length in early life predicts lifespan." Proc Natl Acad Sci U S A 109(5):

$528 \quad 1743-1748$.

529 Henriques, C. M., M. C. Carneiro, I. M. Tenente, A. Jacinto and M. G. Ferreira (2013).

530 "Telomerase is required for zebrafish lifespan." PLoS Genet 9(1): e1003214.

$531 \mathrm{Hu}, \mathrm{C} . \mathrm{K}$. and A. Brunet (2018). "The African turquoise killifish: A research organism to study vertebrate aging and diapause." Aging Cell 17(3): e12757.

533 Ibanez-Alamo, J. D., J. Pineda-Pampliega, R. L. Thomson, J. I. Aguirre, A. Diez-Fernandez, 534 B. Faivre, J. Figuerola and S. Verhulst (2018). "Urban blackbirds have shorter telomeres." 535 Biol Lett 14(3): 20180083.

536 Kimura, M., R. C. Stone, S. C. Hunt, J. Skurnick, X. Lu, X. Cao, C. B. Harley and A. Aviv 537 (2010). "Measurement of telomere length by the Southern blot analysis of terminal restriction 538 fragment lengths." Nat Protoc 5(9): 1596-1607.

539 Kota, L. N., S. Bharath, M. Purushottam, N. S. Moily, P. T. Sivakumar, M. Varghese, P. K. $540 \quad$ Pal and S. Jain (2015). "Reduced telomere length in neurodegenerative disorders may suggest 541 shared biology." J Neuropsychiatry Clin Neurosci 27(2): e92-96.

542 Lai, T. P., W. E. Wright and J. W. Shay (2018). "Comparison of telomere length

543 measurement methods." Philos Trans R Soc Lond B Biol Sci 373(1741): 20160451.

544 Lapham, K., M. N. Kvale, J. Lin, S. Connell, L. A. Croen, B. P. Dispensa, L. Fang, S.

545 Hesselson, T. J. Hoffmann, C. Iribarren, E. Jorgenson, L. H. Kushi, D. Ludwig, T.

546 Matsuguchi, W. B. McGuire, S. Miles, C. P. Quesenberry, Jr., S. Rowell, M. Sadler, L. C.

547 Sakoda, D. Smethurst, C. P. Somkin, S. K. Van Den Eeden, L. Walter, R. A. Whitmer, P. Y.

548 Kwok, N. Risch, C. Schaefer and E. H. Blackburn (2015). "Automated assay of telomere

549 length measurement and informatics for 100,000 subjects in the genetic epidemiology

550 research on adult health and aging (GERA) cohort." Genetics 200(4): 1061-1072. 
Lex, K., Gil, M. M., Lopes-Bastos, B., Figueira, M., Marzullo, M., Giannetti, K., Carvalho, T. and M. G. Ferreira (2020). "Telomere shortening produces an inflammatory environment that increases tumor incidence in zebrafish." Proc Natl Acad Sci U S A, 117(26): 15066-15074.

López-Otín, C., Blasco, M. A., Partridge, L., Serrano, M. and G. Kroemer (2013). "The hallmarks of aging." Cell 153(6): 1194-1217.

Martinez, P. and M. A. Blasco (2018). "Heart-Breaking Telomeres." Circ Res 123(7): 787 802.

560 Monaghan, P. and S. E. Ozanne (2018). "Somatic growth and telomere dynamics in

561 vertebrates: relationships, mechanisms and consequences." Philos Trans R Soc Lond B Biol

562 Sci 373(1741): 20160446.

563 Moskalev, A. A., M. V. Shaposhnikov, E. N. Plyusnina, A. Zhavoronkov, A. Budovsky, H.

564 Yanai and V. E. Fraifeld (2013). "The role of DNA damage and repair in aging through the

565 prism of Koch-like criteria." Ageing Res Rev 12(2): 661-684.

566 Olovnikov, A. M. (1973). "A theory of marginotomy. The incomplete copying of template

567 margin in enzymic synthesis of polynucleotides and biological significance of the

568 phenomenon." J Theor Biol 41(1): 181-190.

569 Opresko, P. L., J. Fan, S. Danzy, D. M. Wilson, 3rd and V. A. Bohr (2005). "Oxidative 570 damage in telomeric DNA disrupts recognition by TRF1 and TRF2." Nucleic Acids Res 571 33(4): 1230-1239.

572 Polacik, M., R. Blazek and M. Reichard (2016). "Laboratory breeding of the short-lived 573 annual killifish Nothobranchius furzeri." Nat Protoc 11(8): 1396-1413.

574 Reichard, M. and M. Polacik (2019). "Nothobranchius furzeri, an 'instant' fish from an 575 ephemeral habitat." eLife 8: e41548.

576 Roos, W. P. and B. Kaina (2006). "DNA damage-induced cell death by apoptosis." Trends $577 \quad$ Mol Med 12(9): 440-450.

578 Rudolph, K. L., S. Chang, H. W. Lee, M. Blasco, G. J. Gottlieb, C. Greider and R. A.

579 DePinho (1999). "Longevity, stress response, and cancer in aging telomerase-deficient mice."

$580 \quad$ Cell 96(5): 701-712.

581 Salomons, H. M., G. A. Mulder, L. van de Zande, M. F. Haussmann, M. H. Linskens and S.

582 Verhulst (2009). "Telomere shortening and survival in free-living corvids." Proc Biol Sci

583 276(1670): 3157-3165.

584 Seluanov, A., Z. Chen, C. Hine, T. H. Sasahara, A. A. Ribeiro, K. C. Catania, D. C.

585 Presgraves and V. Gorbunova (2007). "Telomerase activity coevolves with body mass not

586 lifespan." Aging Cell 6(1): 45-52. 

Rai (2016). "Role of telomeres and associated maintenance genes in Type 2 Diabetes Mellitus: A review." Diabetes Res Clin Pract 122: 92-100.

590 Sherr, C. J. and R. A. DePinho (2000). "Cellular senescence: mitotic clock or culture shock?" 591 Cell 102(4): 407-410.

592 Tozzini, E. T., A. Dorn, E. Ng'oma, M. Polacik, R. Blazek, K. Reichwald, A. Petzold, B. 593 Watters, M. Reichard and A. Cellerino (2013). "Parallel evolution of senescence in annual 594 fishes in response to extrinsic mortality." BMC Evol Biol 13: 77.

595 Tsakiri, K. D., J. T. Cronkhite, P. J. Kuan, C. Xing, G. Raghu, J. C. Weissler, R. L.

596 Rosenblatt, J. W. Shay and C. K. Garcia (2007). "Adult-onset pulmonary fibrosis caused by 597 mutations in telomerase." Proc Natl Acad Sci U S A 104(18): 7552-7557.

598 Udroiu, I. (2020). "On the correlation between telomere shortening rate and life span." Proc $599 \quad$ Natl Acad Sci U S A 117(5): 2248-2249.

600 Vrtilek, M., J. Zak, M. Polacik, R. Blazek and M. Reichard (2018b). "Longitudinal 601 demographic study of wild populations of African annual killifish." Sci Rep 8(1): 4774.

602 Vrtilek, M., J. Zak, M. Psenicka and M. Reichard (2018a). "Extremely rapid maturation of a 603 wild African annual fish." Curr Biol 28(15): R822-R824.

604 Vulliamy, T., A. Marrone, R. Szydlo, A. Walne, P. J. Mason and I. Dokal (2004). "Disease 605 anticipation is associated with progressive telomere shortening in families with dyskeratosis 606 congenita due to mutations in TERC." Nat Genet 36(5): 447-449.

607 Whittemore, K., E. Vera, E. Martinez-Nevado, C. Sanpera and M. A. Blasco (2019).

608 "Telomere shortening rate predicts species life span." Proc Natl Acad Sci U S A 116(30): 609 15122-15127.

610 Wilbourn, R. V., J. P. Moatt, H. Froy, C. A. Walling, D. H. Nussey and J. J. Boonekamp 611 (2018). "The relationship between telomere length and mortality risk in non-model vertebrate 612 systems: a meta-analysis." Philos Trans R Soc Lond B Biol Sci 373(1741).

613 Willemsen D., C. R., Reichard M and D. R. Valenzano (2020). "Intra-species differences in 614 population size shape life history and genome evolution." eLife (accepted).

615 Yamaguchi, H., R. T. Calado, H. Ly, S. Kajigaya, G. M. Baerlocher, S. J. Chanock, P. M. 616 Lansdorp and N. S. Young (2005). "Mutations in TERT, the gene for telomerase reverse 617 transcriptase, in aplastic anemia." N Engl J Med 352(14): 1413-1424.

618 Zhang, J., G. Rane, X. Dai, M. K. Shanmugam, F. Arfuso, R. P. Samy, M. K. Lai, D. Kappei, 619 A. P. Kumar and G. Sethi (2016). "Ageing and the telomere connection: An intimate 620 relationship with inflammation." Ageing Res Rev 25: 55-69. 
622 Zuur, A. F. and E. N. Ieno (2016). "A protocol for conducting and presenting results of 623 regression-type analyses. " Meth Ecol Evol, 7: 636-645.

624 


\section{FIGURES}

626 Fig. 1. Geographic origin of study strains along the cline of precipitation, with male (larger)

627 and female (smaller) Nothobranchius furzeri inset. Median lifespan (sexes pooled) is

628 visualized by intensity of coloration for each original strain location (red: shortest lifespan;

629 white: longest lifespan). Sex differences in fish body size are proportional.

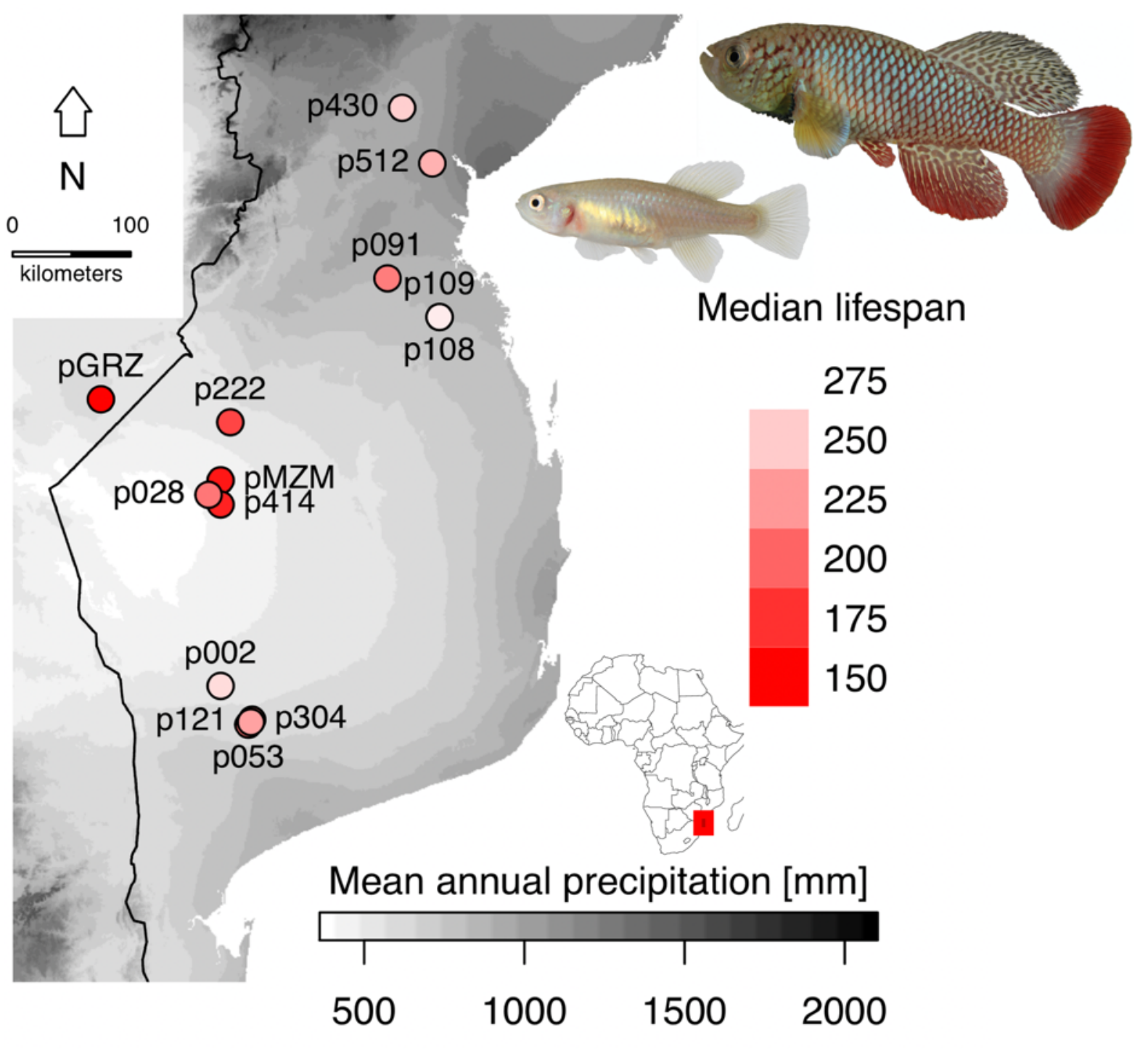

631 
632 Fig. 2. Relationship between median lifespan of males (blue) and females (red) and mean

633 annual precipitation in their region of origin. Lines were fitted using linear regression.

634

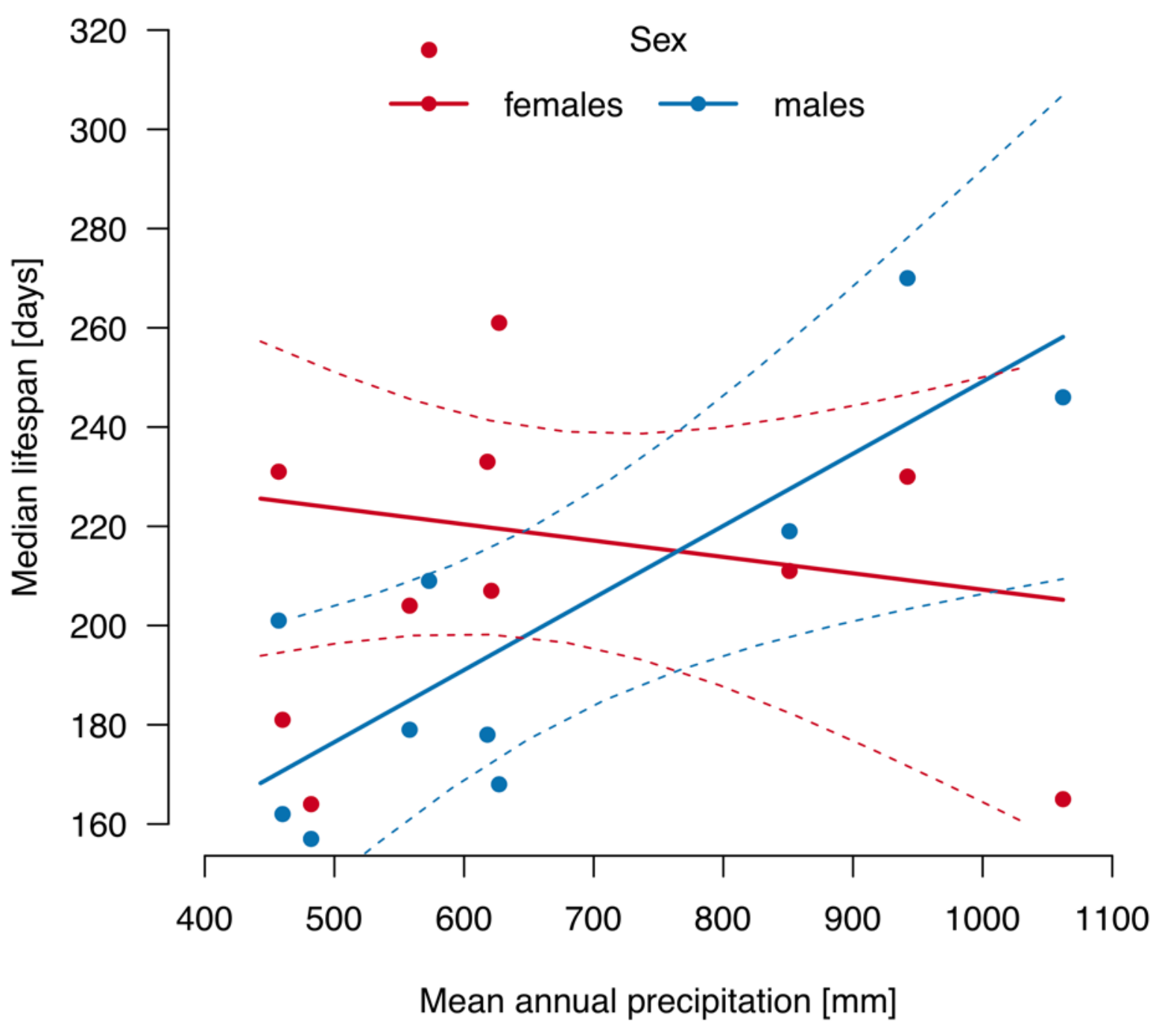

636 
637 Fig. 3. Biplot visualization of telomere length distribution parameters, based on Principal

638 Component analysis. Vectors represent estimated parameters; the numbers denote sample ID.

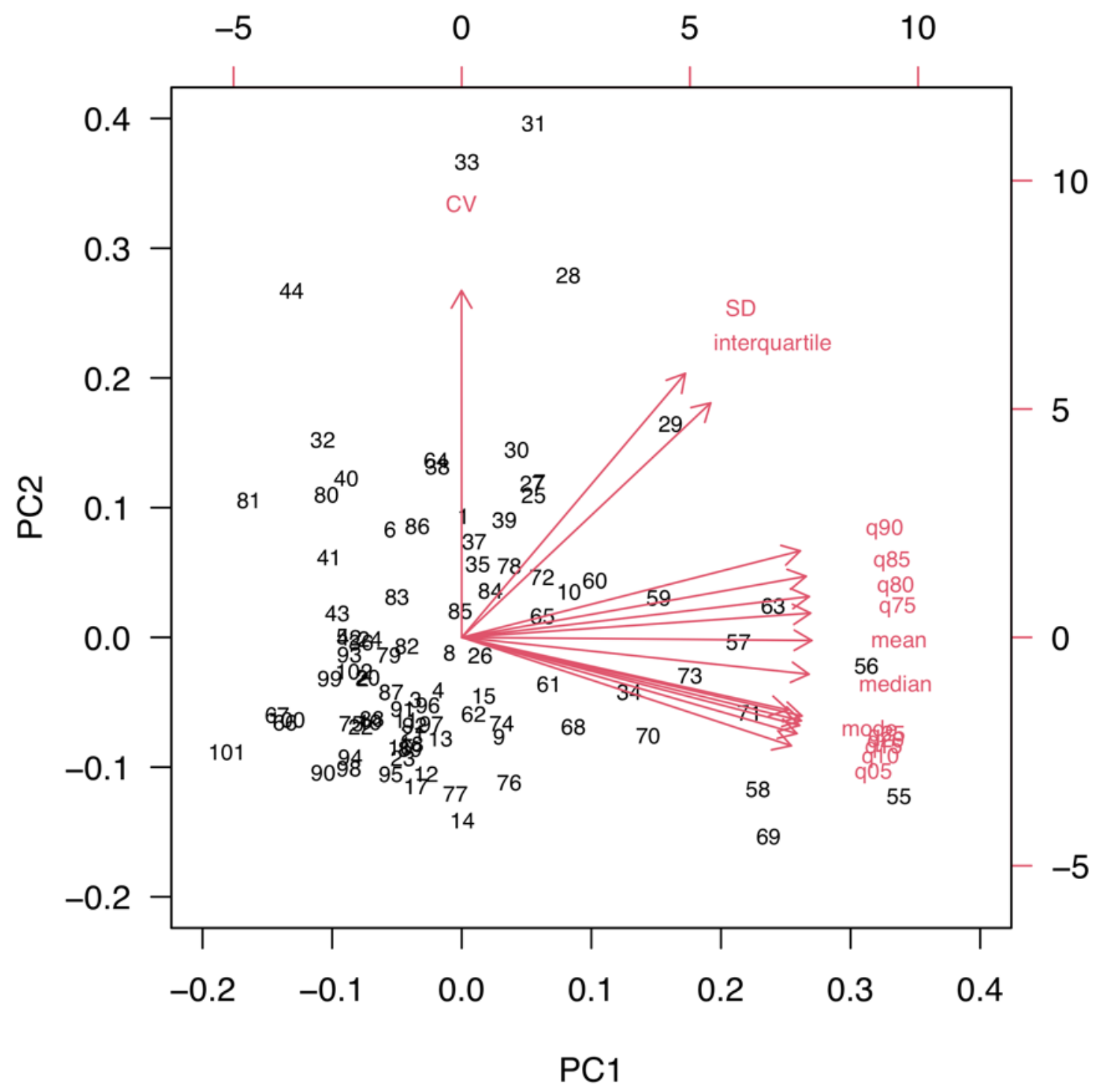

639

640 
641 Fig. 4. Among strains variability in (A) mean telomere length and (B) intra-individual

642 variation in telomere length, estimated as Coefficient of Variation (CV). Strains are ranked

643 from shortest to longest telomere length.

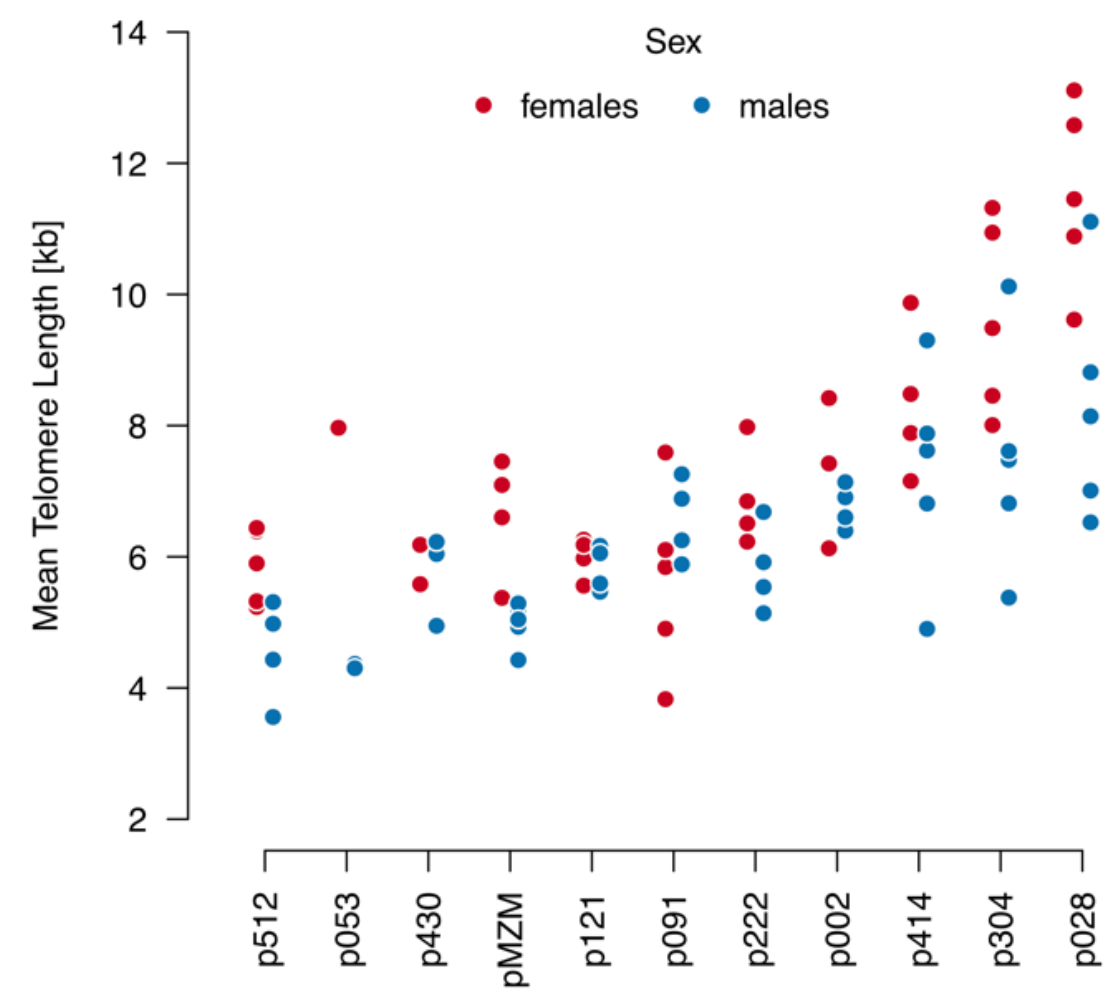

644
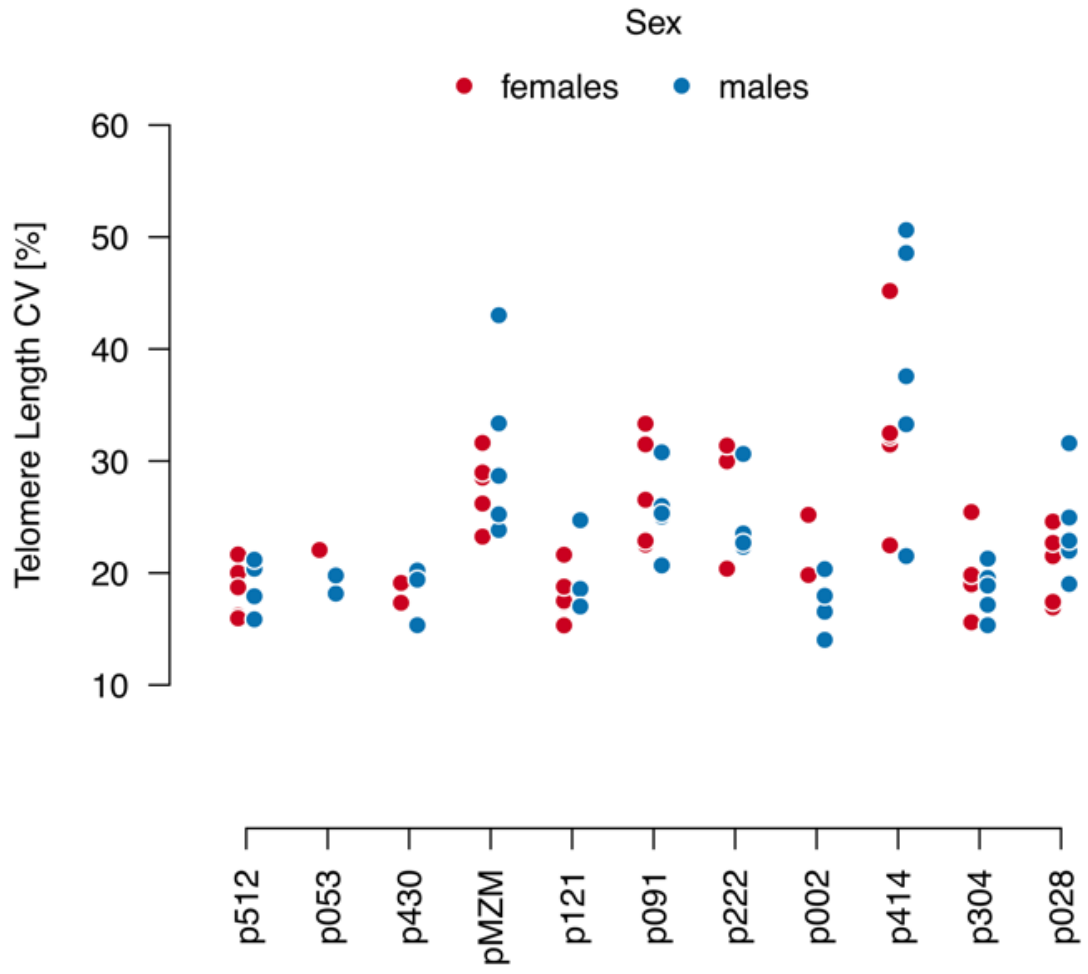
646 Fig. 5. Relationship between mean telomere length and mean annual precipitation in male

647 (blue) and female (red) killifish. Solid lines represent relationship fitted with a mixed model

648 including sex and precipitation as fixed factors and strain ID as a random factor.

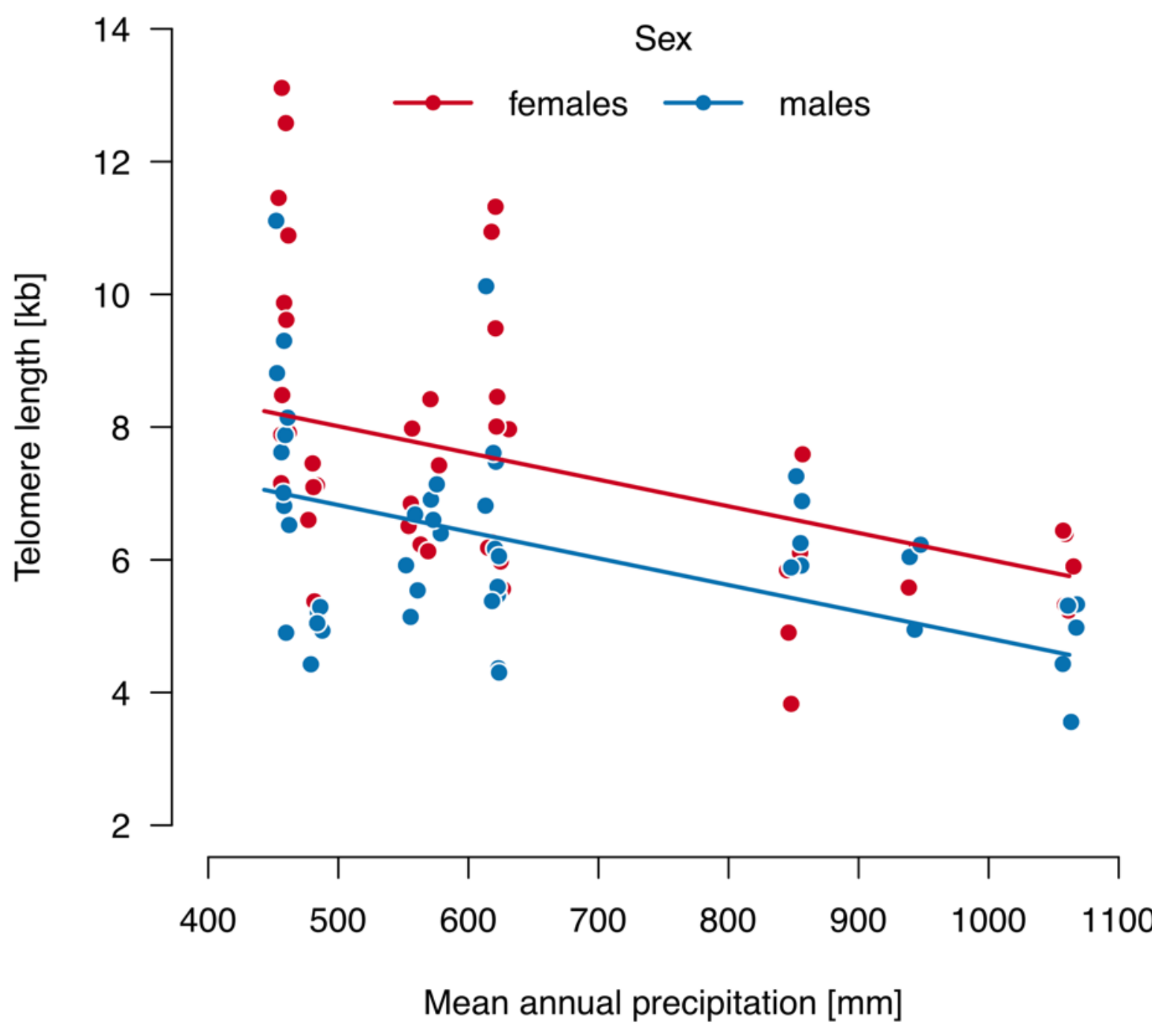

649

650 
651 Fig. 6. Relationship between telomere length and sex-specific strain-level lifespan estimates.

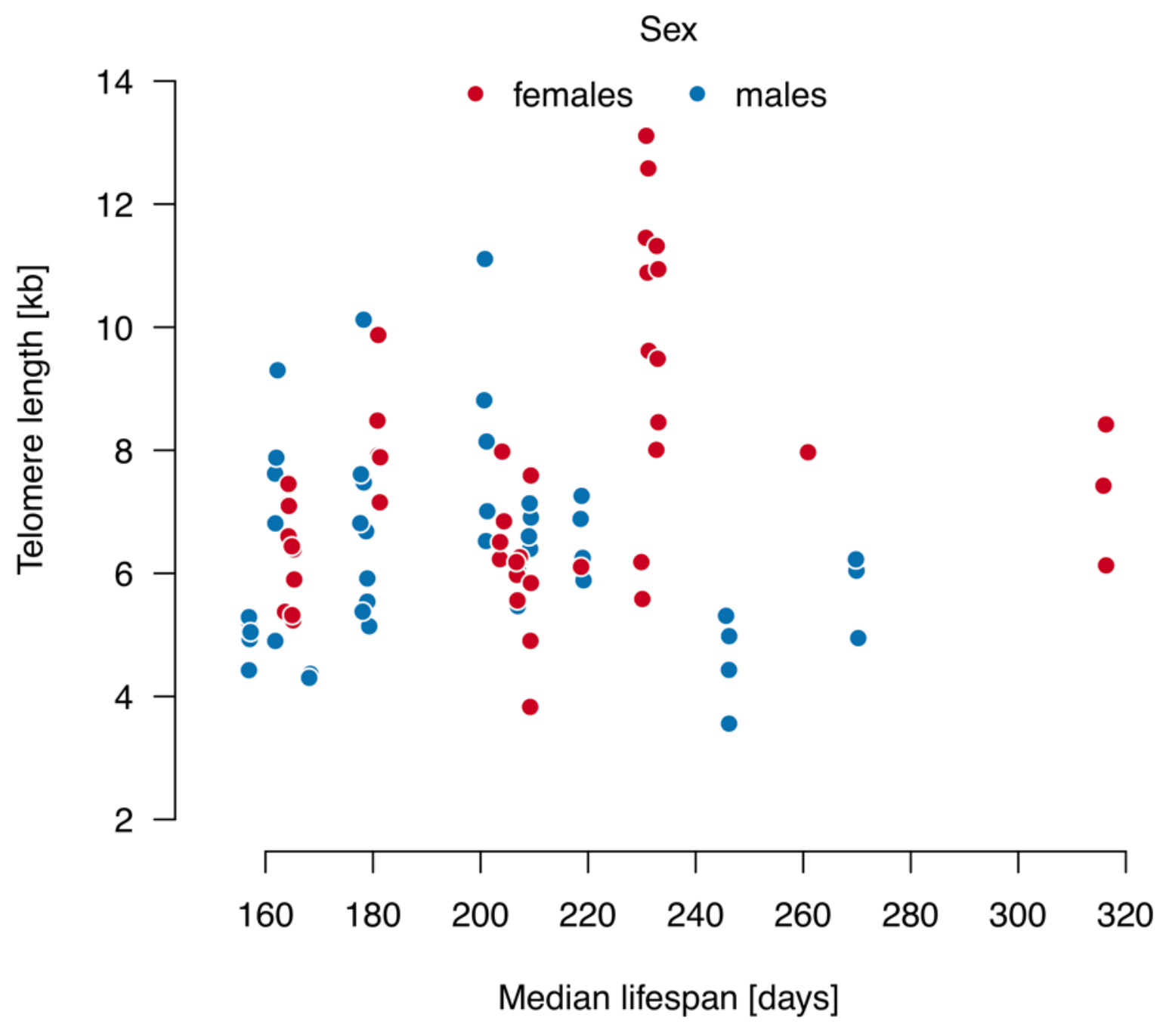

653 
Table 1. List of all strains from the N. furzeri-N. kadleci species complex used in the study. Populations are ordered according to median lifespan. Precipitation represents mean annual precipitation total, aridity is the index of aridity calculated from precipitation-evaporation differentials (both derived from CGIAR Consortium for Spatial Information: www.cgiar-csi.org). Sample sizes for telomere length study (telomeres) and longevity estimates ( $\mathrm{N}$ fish) are shown. Median lifespan was calculated using the surv function in the survival package.

\begin{tabular}{|c|c|c|c|c|c|c|c|c|c|c|c|}
\hline Pop & Clade & $\begin{array}{l}\text { Collection } \\
\text { Year }\end{array}$ & Precip & Aridity & Lat & Long & $\begin{array}{c}\text { Telomeres } \\
(\text { Nmale,fem) }\end{array}$ & $\begin{array}{l}\text { Median lifespan } \\
\quad(95 \% \mathrm{CI})\end{array}$ & $\mathrm{N}$ fish & $\begin{array}{l}\text { Median lifespan } \\
(95 \% \text { CI }) \text { Females }\end{array}$ & $\begin{array}{l}\text { Median lifespan } \\
(95 \% \text { CI }) \text { Males }\end{array}$ \\
\hline pGRZ & Chefu & 1969 & 588 & 0.3264 & -21.68 & 31.73 & (3) & $151(136-174)$ & 29 & $155(131-178)$ & 148 (111-NA) \\
\hline pMZM & Chefu & 2004 & 482 & 0.2657 & -22.35 & 32.72 & 5,5 & $162(140-203)$ & 33 & $164(136-220)$ & $157(124-203)$ \\
\hline p414 & Chefu & 2012 & 460 & 0.2523 & -22.55 & 32.72 & 5,5 & $168(162-176)$ & 47 & $181(165-183)$ & $162(136-168)$ \\
\hline p222 & Chefu & 2011 & 558 & 0.3082 & -21.87 & 32.8 & 4,4 & $185(137-203)$ & 45 & 204 (119-218) & 179 (126-195) \\
\hline p028 & Chefu & 2013 & 457 & 0.251 & -22.47 & 32.62 & 5,5 & $209(177-233)$ & 45 & $231(182-264)$ & $201(154-229)$ \\
\hline p024 & Chefu & 2010 & 443 & 0.2435 & -22.5 & 32.55 & 5,5 & $215(142-246)$ & 43 & $228(112-264)$ & $209(118-246)$ \\
\hline p304 & Limpopo & 2013 & 618 & 0.3395 & -24.33 & 32.98 & 5,5 & $215(180-240)$ & 35 & $233(200-276)$ & $178(137-237)$ \\
\hline p121 & Limpopo & 2011 & 621 & 0.3426 & -24.35 & 32.97 & 4,5 & $230(206-265)$ & 49 & $274(2014301)$ & $207(174-221)$ \\
\hline p002 & Limpopo & 2012 & 573 & 0.3203 & -24.05 & 32.72 & 4,3 & $258(218-287)$ & 46 & $316(240-350)$ & $209(183-260)$ \\
\hline p091 & N. kadleci & 2010 & 851 & 0.5114 & -20.68 & 34.1 & 5,5 & $212(179-226)$ & 49 & $209(122-224)$ & $219(173-250)$ \\
\hline p512 & N. kadleci & 2012 & 1065 & 0.6390 & -19.73 & 34.47 & 5,5 & $238(165-257)$ & 43 & $165(83-249)$ & $246(198-292)$ \\
\hline p430 & N. kadleci & 2011 & 939 & 0.5051 & -19.27 & 34.22 & 3,2 & $252(229-275)$ & 48 & $230(183-271)$ & $270(231-270)$ \\
\hline p109 & N. kadleci & 2010 & 847 & 0.5357 & -21.00 & 34.53 & No & $266(211-287)$ & 45 & $289(265-298)$ & $211(175-266)$ \\
\hline p108 & N. kadleci & 2008 & 847 & 0.5357 & -21.00 & 34.53 & No & $276(177-288)$ & 41 & $288(233-301)$ & $186(105-284)$ \\
\hline
\end{tabular}


Table 2. List of candidate models to test the relationship of mean telomere length (a) and its intra-individual variation (b) with sex and juvenile growth. Model structure (fixed effects and their interaction, and random effect of strain ID), degrees of freedom (d.f.), Akaike Information Criterion corrected for small sample size (AICc), difference between the best fitting model and candidate model ( $\triangle \mathrm{AICc})$ indicating strength of support for a particular model, amount of variability explained by fixed effects $\left(\mathrm{R}^{2}\right.$ marginal $)$ and by combination of fixed and random effects

( $\mathrm{R}^{2}$ conditional).

\begin{tabular}{|c|c|c|c|c|c|c|}
\hline \multicolumn{2}{|l|}{ Model } & d.f. & $\mathrm{AICc}$ & $\Delta \mathrm{AICs}$ & R2 marginal & $\mathrm{R} 2$ conditional \\
\hline \multicolumn{7}{|c|}{ (a) Mean telomere length } \\
\hline M0 & (1|pop) & 3 & 343.6612 & 17.4639 & 0,000 & 0.5235916 \\
\hline M1 & $\operatorname{sex}+(1 \mid p o p)$ & 4 & 326.1973 & 0 & 0.09654603 & 0.6228926 \\
\hline M2 & sex + body $+(1 \mid$ pop $)$ & 5 & 328.1906 & 1.9933 & 0.1331258 & 0.6611852 \\
\hline M3 & sex + body + sex:body $+(1 \mid$ pop $)$ & 6 & 333.9235 & 7.7262 & 0.1331096 & 0.6589753 \\
\hline M4 & body $+(1 \mid$ pop $)$ & 4 & 334.4206 & 8.2233 & 0.1355438 & 0.6662607 \\
\hline
\end{tabular}

(b) Coefficient of variation

\begin{tabular}{llccccc}
\hline M0 & $(1 \mid$ pop $)$ & 3 & -255.5706 & 0 & 0 & 0.5459538 \\
M1 & sex + (1|pop) & 4 & -246.4165 & 9,1541 & 0.00171725 & 0.5455763 \\
M2 & sex + body + (1|pop) & 5 & -235.5418 & 20,0288 & 0.02346989 & 0.5503774 \\
M3 & sex + body + sex:body $+(1 \mid$ pop $)$ & 6 & -223.6337 & 31,9369 & 0.02662207 & 0.5501118 \\
M4 & body + (1|pop) & 4 & -244.7485 & 10,8221 & 0.02161716 & 0.5520438 \\
\hline
\end{tabular}


Table 3. List of candidate models to test the relationship of mean telomere length (a) and its intra-individual variation (b) with precipitation.

Model structure (fixed effects and their interaction, and random effect of strain ID), degrees of freedom (d.f.), Akaike Information Criterion corrected for small sample size (AICc), difference between the best fitting model and candidate model ( $\triangle \mathrm{AICc}$ ) indicating strength of support for a particular model, amount of variability explained by fixed effects $\left(\mathrm{R}^{2}\right.$ marginal $)$ and by combination of fixed and random effects $\left(\mathrm{R}^{2}\right.$ conditional).

\begin{tabular}{lrrrrrr}
\hline \multicolumn{1}{l}{ Model } & \multicolumn{1}{l}{ d.f. } & AICc & $\Delta$ AICs & R2 marginal & R2 conditional \\
\hline (a) Mean telomere length & & & & & \\
\hline M0 & (1|pop) & 3 & 343.6612 & -8.341 & 0 & 0.5235916 \\
M1 & precip $+(1 \mid$ pop $)$ & 4 & 352.6750 & -17.3548 & 0.1741896 & 0.5407045 \\
M2 & precip + sex $+(1 \mid$ pop $)$ & 5 & 335.3202 & 0 & 0.2649685 & 0.6376086 \\
M3 & precip + sex + precip:sex $+(1 \mid$ pop $)$ & 6 & 344.3068 & -8.9866 & 0.2844145 & 0.6560993 \\
\hline
\end{tabular}

\section{(b) Coefficient of variation}

\begin{tabular}{llrrrrr}
\hline M0 & $(1 \mid$ pop $)$ & 3 & -255.5706 & 0 & 0 & 0.5459538 \\
M1 & precip $+(1 \mid$ pop $)$ & 4 & -238.9254 & 16.6452 & 0.1275769 & 0.5670824 \\
M2 & precip + sex $+(1 \mid$ pop $)$ & 5 & -229.7255 & 25.8451 & 0.1286001 & 0.5665069 \\
M3 & precip + sex + precip:sex $+(1 \mid$ pop $)$ & 6 & -211.1557 & 44.4149 & 0.1348708 & 0.5715629 \\
\hline
\end{tabular}


Table 4. List of candidate models to test the relationship of mean telomere length (a) and its intra-individual variation (b) with median sexspecific strain-level lifespan estimates. Model structure (fixed effects and their interaction, and random effect of strain ID), degrees of freedom (d.f.), Akaike Information Criterion corrected for small sample size (AICc), difference between the best fitting model and candidate model ( $\triangle \mathrm{AICc})$ indicating strength of support for a particular model, amount of variability explained by fixed effects $\left(\mathrm{R}^{2}\right.$ marginal) and by combination of fixed and random effects ( $\mathrm{R}^{2}$ conditional).

\begin{tabular}{|c|c|c|c|c|c|c|}
\hline Model & & d.f. & $\mathrm{AICc}$ & $\Delta \mathrm{AICs}$ & $\mathrm{R} 2$ marginal & $\mathrm{R} 2$ conditional \\
\hline \multicolumn{7}{|c|}{ (a) Mean telomere length } \\
\hline M0 & (1|pop) & 3 & 343.6612 & 8.7919 & 0 & 0.5235916 \\
\hline M1 & lifespan + (1|pop) & 4 & 348.6886 & 13.8193 & 0.0540819 & 0.5801477 \\
\hline M2 & lifespan + sex $+(1 \mid$ pop $)$ & 5 & 334.8693 & 0 & 0.1116633 & 0.6378792 \\
\hline M3 & lifespan + sex + lifespan:sex $+(1 \mid$ pop $)$ & 6 & 343.9329 & 9.0636 & 0.1139724 & 0.6578448 \\
\hline
\end{tabular}

\section{(b) Coefficient of variation}

\begin{tabular}{|c|c|c|c|c|c|c|}
\hline M0 & (1|pop) & 3 & -255.5706 & 0 & 0 & 0.5459538 \\
\hline M1 & lifespan $+(1 \mid$ pop $)$ & 4 & -238.2521 & 17.3185 & 0.0009664 & 0.5333689 \\
\hline M2 & lifespan + sex $+(1 \mid$ pop $)$ & 5 & -229.0534 & 26.5172 & 0.0019424 & 0.5387066 \\
\hline M3 & lifespan + sex + lifespan:sex $+(1 \mid$ pop $)$ & 6 & -216.2014 & 39.3692 & 0.0307574 & 0.5483350 \\
\hline
\end{tabular}

